\title{
Comparing apples and oranges will not guide treatment the right way in umbilical hernia repair: use either level-1 evidence or guidelines
}

\author{
R. Kaufmann ${ }^{1,2}$ D J. A. Halm ${ }^{3}$ D . J. F. Lange ${ }^{2}$ (D)
}

Received: 28 March 2020 / Accepted: 9 April 2020

c) Springer-Verlag France SAS, part of Springer Nature 2020

Keywords Umbilical hernia $\cdot$ Ventral hernia $\cdot$ Incisional hernia $\cdot$ Abdominal wall hernia $\cdot$ Recurrence

Dear Sir,

We write in response to the recently published study by Mitura et al. entitled "Is mesh always necessary in every small umbilical hernia repair? Comparison of standardized primary sutured versus patch repair: retrospective cohort study" [1]. The authors investigated 161 patients: 104 patch repairs and 57 suture repairs and concluded that for the smallest umbilical hernias, the use of suture repair may be an effective alternative to patch repair techniques in patients with no additional risk factors for recurrence. They found that patch repair was associated with a significantly higher risk of postsurgical pain. The follow-up was performed by a telephone interview.

Some initial statements in the manuscript are incorrect. For example, the study by Arroyo et al. is introduced suggesting that small hernias in that study were treated with a flat mesh and that it was not reported that the orifice was widened to place the mesh. Arroyo treated hernia defects up to $3 \mathrm{~cm}$ with a mesh plug repair, whereas a mesh sheet was inserted for larger hernias only [2]. Thereafter, suture

\footnotetext{
R. Kaufmann

ruth.kaufmann@gmail.com

J. A. Halm

j.a.halm@amc.uva.nl

J. F. Lange

j.lange@erasmusmc.nl

1 Department of Radiology, Haga Teaching Hospital, Els Borst-Eilersplein 275, 2545 AA The Hague, The Netherlands

2 Department of Surgery, Erasmus University Medical Center, Rotterdam, The Netherlands

3 Department of Traumasurgery, Amsterdam University Medical Centres, Location AMC, Amsterdam, The Netherlands
}

techniques are mentioned referring to an article on open repair of predominantly incisional hernia and another paper on laparoscopic ventral hernia repair, not comparable to the research presented in this study [3,4].

In short, from a large randomized controlled trial, there is strong evidence in favour of flat mesh for hernia diameters $\geq 1 \mathrm{~cm}$ [5]. In a large database study with similar patient characteristics as in the current study, there is also good evidence for mesh in case of hernia diameters smaller than $1 \mathrm{~cm} \mathrm{[6].} \mathrm{We,} \mathrm{therefore,} \mathrm{consider} \mathrm{the} \mathrm{comparison} \mathrm{between}$ patch repair (known for more postoperative complications including postoperative pain from randomized investigation [7]) and suture repair a comparison between two "inferior" techniques and would like to emphasize that flat mesh reinforcement outperforms suture repair (and patches) even in small umbilical hernias in all studies. Ignoring this evidence and the current American and European Hernia Society guidelines is a disservice to patients with an umbilical hernia. Suture repair should be used as "second best" in selected patients with small umbilical hernia defects $(<1 \mathrm{~cm})$ without diastasis recti, in patients that refuse mesh, and in women of childbearing age that wish to become pregnant $[8,9]$.

Funding No funding was received for this contribution.

\section{Compliance with ethical standards}

Conflict of interest None of the authors has any conflicts of interests to report.

Ethical approval This article does not contain any studies with human participants or animals performed by the authors.

Human and animal rights This article does not contain any study with animals performed by the author. 
Informed consent For this type of article, informed consent is not required.

\section{References}

1. Mitura K, Skolimowska-Rzewuska M, Rzewuska A, Wyrzykowska D (2020) Is mesh always necessary in every small umbilical hernia repair? Comparison of standardized primary sutured versus patch repair: retrospective cohort study. Hernia. https://doi.org/10.1007/s10029-020-02170-1

2. Arroyo A, Garcia P, Perez F, Andreu J, Candela F, Calpena R (2001) Randomized clinical trial comparing suture and mesh repair of umbilical hernia in adults. Br J Surg 88(10):1321-1323

3. Mathes T, Walgenbach M, Siegel R (2016) Suture versus mesh repair in primary and incisional ventral hernias: a systematic review and meta-analysis. World J Surg 40(4):826-835

4. Nguyen DH, Nguyen MT, Askenasy EP, Kao LS, Liang MK (2014) Primary fascial closure with laparoscopic ventral hernia repair: systematic review. World J Surg 38(12):3097-3104

5. Kaufmann R, Halm JA, Eker HH, Klitsie PJ, Nieuwenhuizen J, van Geldere D et al (2018) Mesh versus suture repair of umbilical hernia in adults: a randomised, double-blind, controlled, multicentre trial. Lancet 391(10123):860-869

6. Christoffersen MW, Helgstrand F, Rosenberg J, Kehlet H, Bisgaard $\mathrm{T}$ (2013) Lower reoperation rate for recurrence after mesh versus sutured elective repair in small umbilical and epigastric hernias. A nationwide register study. World J Surg 37(11):2548-2552

7. Ponten JEH, Leclercq WKG, Lettinga T, Heemskerk J, Konsten JLM, Bouvy ND et al (2019) Mesh OR patch for hernia on epigastric and umbilical sites (MORPHEUS-trial): the complete 2-year follow-up. Ann Surg 270(1):33-37

8. Henriksen NA, Montgomery A, Kaufmann R, Berrevoet F, East B, Fischer J et al (2020) Guidelines for treatment of umbilical and epigastric hernias from the European Hernia Society and Americas Hernia Society. Br J Surg 107(3):171-190

9. Henriksen NA, Kaufmann R, Simons MP, Berrevoet F, East B, Fischer J et al (2020) EHS and AHS guidelines for treatment of primary ventral hernias in rare locations or special circumstances. BJS Open 4(2):342-353

Publisher's Note Springer Nature remains neutral with regard to jurisdictional claims in published maps and institutional affiliations. 